Gut, 1978, 19, 823-826

\title{
Suppression of rejection of Nippostrongylus brasiliensis in iron and protein deficient rats: effect of syngeneic lymphocyte transfer
}

\author{
A. G. CUMMINS, V. M. DUNCOMBE, T. D. BOLIN, A. E. DAVIS, AND \\ J. D. KELLY
}

From the University of New South Wales, Gastrointestinal Unit, Prince of Wales Hospital, and Department of Veterinary Pathology, University of Sydney, New South Wales, Australia

SUMMARY Rejection of Nippostrongylus brasiliensis is impaired in iron and protein deficient rats and this suggests that iron and protein deficiency directly or indirectly suppresses the immune response. The site of the immunological defect in deficient rats was investigated using the technique of cellular transfer of resistance. The functional activity of immune mesenteric lymph node cells obtained from iron and protein deficient donors was not depressed as measured by their capacity to cause parasite rejection in nutritionally sufficient recipients. In contrast, immune lymph node cells obtained from either sufficient or deficient donors did not result in parasite rejection in iron and protein deficient recipients. These results indicate that there is no permanent defect of lymphocyte function in iron and protein deficient rats and suggest that either some other component of the rejection mechanism is defective, or that lymphocyte function is blocked in an iron and protein deficient environment.

Helminthiasis remains a major problem in many parts of the world, particularly in developing countries where an association malnutrition is common. A variety of factors are involved in this association, including the ability of gut parasites to contribute to the diarrhoea/malnutrition cycle (Stanfield, 1966). Dietary or parasite induced malnutrition may potentiate helminth infections by reducing the capacity of the host to mount a protective immune response.

Evidence that malnutrition potentiates parasite survival through impairment of the host immune response has been provided by a series of experiments using the Nippostrongylus brasiliensis-rat model. In this system, rats infected with $N$. brasiliensis normally develop an actively acquired immunity and thereafter are resistant to subsequent infection. However, in iron and protein deficient rats, worm expulsion following a primary infection is delayed (Bolin et al., 1977) and acquired resistance to reinfection is substantially impaired (Duncombe et al., 1978).

Recent studies have shown that the immune response which initiates expulsion of $N$. brasiliensis from the gut is at least a four-step process. In the

Received for publication 7 March 1978 first step, antibodies initiate biochemical and morphological damage to worms (Jones and Ogilvie, 1971) which then become susceptible to the second and third steps for which sensitised lymphocytes (Kelly and Dineen, 1972) and a bone marrow derived component (Dineen and Kelly, 1973) are required. In the fourth step, sensitised lymphocytes and the bone marrow derived component interact with various mediators of inflammation such as prostaglandins (Kelly et al., 1974) finally to effect worm expulsion. Although the precise sequence of events has not been determined, it is known that antibody triggered damage must occur before sensitised lymphocytes can initiate the immunologically nonspecific phase of worm expulsion involving pharmacological mediators (Kelly et al., 1974).

As worm expulsion is an immunological process, it is reasonable to assume that delayed expulsion of $N$. brasiliensis is due to a defect of one or more components of the immune response. In a previous study it was reported that antibody mediated damage occurred normally in iron and protein deficient rats even though rejection was impaired (Bolin et al., 1977). This would suggest that failure of worm expulsion is due to a defect in either sensitised lymphocytes or immunologically non-specific components of the immune response. Thus the aim of 
this study was to determine whether functional lymphoid cells are produced by iron and protein rats infected with $N$. brasiliensis. This was assessed using the cell transfer technique described by Kelly and Dineen (1972).

\section{Methods}

\section{ANIMALS}

Donor and recipient animals were highly inbred DA rats of both sexes (Dineen et al., 1973).

\section{PARASITE}

Third stage larvae of $N$. brasiliensis were obtained from charcoal cultures of faeces (Leigh, 1956). Methods of infection and estimation of total worm counts have been described (Kelly and Dineen, 1972).

\section{PREPARATION OF IRON AND PROTEIN \\ DEFICIENT ANIMALS}

Synthetic diets were prepared which were either sufficient or deficient in iron and protein. A sufficient diet contained $30 \%$ protein, $50 \%$ carbohydrate, and $9.6 \%$ fat with vitamin and mineral supplements. An isocaloric iron and protein deficient diet contained no iron supplement and only $10 \%$ protein (Bolin et al., 1971). Blood was collected for haemoglobin before inoculation with larvae and albumin estimations were carried out at the time of necropsy for total worm counts.

\section{IMMUNISATION OF CELL DONORS}

Donors for cell transfer were infected twice with 1000 third stage larvae of $N$. brasiliensis at 21 and seven days before removal of mesenteric lymph nodes.

PREPARATION AND TRANSFER OF SYNGENEIC LYMPH NODE CELLS

The method described by Kelly and Dineen (1972) was followed. The peritoneal cavity was opened using a sterile technique. Mesenteric lymph nodes were removed from donors, dissected free of fat, and placed in chilled Hanks solution (pH 7.3). The lymph nodes were then diced with fine scissors, and the diced fragments vigorously drawn up and down with a wide-mouthed pipette. The fragments were filtered through sterile gauze and the resulting cell suspension centrifuged for six minutes at $200 \mathrm{~g}$. The supernatant was removed, the cells resuspended in fresh Hank's solution and centrifuged again. After removal of the supernatant, washed cells were resuspended in fresh chilled Hank's solution and the number of cells $/ \mathrm{ml}$ estimated using a haemocytometer. Viability was assessed by the capacity of cells to exclude $2 \%$ Trypan blue. The volume of the cell suspension was then adjusted so that $1 \mathrm{ml}$ contained
$125 \times 10^{6}$ viable cells and this was transferred to recipients within two hours of killing donors by intravenous injection into the lateral tail veins.

\section{STATISTICS}

Body weight, haemoglobin, and serum albumin levels were analysed by Student's $t$ test. Analysis of variance was carried out on all worm count data after transformation to $\log _{10}(x+1)$, and individual comparisons made with Student's $t$ test.

\section{Experimental design and results}

Three week old DA rats were weaned onto synthetic diets either sufficient or deficient in iron and protein. Five weeks later these animals were infected twice with $N$. brasiliensis and acted as either sufficient or deficient cell donors (see Methods section).

Two identical experiments were carried out and the results are pooled. There were five animals in each group in each experiment. Iron and protein sufficient (groups 1, 2, and 5) and deficient (groups 3,4 , and 6) rats were infected with 1000 third stage larvae of $N$. brasiliensis. Groups 5 and 6 received no further treatment and acted as infection controls. At this time, rats in all groups were weighed and had blood collected for haemoglobin levels. On the day of infection, rats in groups 1 and 3 were each injected intravenously with $125 \times 10^{6}$ cells from infected donors sufficient in iron and protein, while those in groups 2 and 4 were each injected intravenously with $125 \times 10^{6}$ cells from infected donors deficient in iron and protein. Ten days later, rats in all groups were killed for total worm counts and blood collected for serum albumin levels. These results are presented in Tables 1 and 2.

Table 1 Body weight, serum albumin, and haemoglobin levels in iron and protein sufficient and deficient rats

\begin{tabular}{llll}
\hline & \multicolumn{2}{l}{ Diptary status } & \\
\cline { 2 - 4 } & $\begin{array}{l}\text { Iron and protein } \\
\text { sufficient }\end{array}$ & $\begin{array}{l}\text { Iron and protein } \\
\text { deficient }\end{array}$ & P value \\
\hline Body weight (g) & $184 \pm 9.1$ & $104 \pm 3.4$ & $<0.01$ \\
Albumin (g/l) & $32.0 \pm 0.3$ & $26.0 \pm 0.2$ & $<0.01$ \\
Haemoglobin (g/dl) & $13.9 \pm 0.2$ & $8.0 \pm 0.1$ & $<0.01$ \\
\hline
\end{tabular}

BODY WEIGHT, SERUM ALBUMIN, AND

HAEMOGLOBIN LEVELS

There was a statistically significant difference in body weight, serum albumin and haemoglobin levels between sufficient and deficient rats, indicating iron and protein deficiency in animals on a deficient diet. 
LYMPHOCYTE YIELDS FROM DONOR RATS

The average total cell yields for mesenteric lymph nodes from deficient individual donors was $139 \times$ $10^{6}$, which was substantially lower than the average of $200 \times 10^{6}$ lymphocytes recovered from donors on a sufficient diet. This difference was significant at the $5 \%$ level. Although the lower recovery may suggest a diminished immune response to $N$. brasiliensis in deficient donors, it may also be related to differences in body weights between the two groups.

\section{TOTAL WORM COUNTS}

The total worm counts performed 10 days after worm infection and cell transfer demonstrated no significant difference between non-recipient infection controls on a sufficient (group 5, mean count 275), or deficient diet (group 6, 320; P> 0.05). By comparison with these non-recipient controls, there was a highly significant reduction in total worm counts in rats on a sufficient diet given cells either from a sufficient (group 1, 5; $\mathrm{P}<0.01$ ) or deficient (group 2, 17; $P<0.01)$ donors. This showed that transferred cells are viable and effective as immune lymphocytes in initiating worm expulsion in normal recipients, regardless of the dietary status of the cell donors.

There was no significant difference between nonrecipient infection controls on a deficient diet (group 6, 320) and iron and protein deficient rats receiving cells from sufficient (group 3, 269) or deficient (group 4, 298) immunised donors. This showed that the defect in $N$. brasiliensis expulsion in deficient rats can not be overcome by transfer of immune lymphocytes known to be fully functional (group 1, Table 2).

Although lymphocytes obtained from immunised nutritionally deficient donors were effective in initiating worm rejection when transferred to recipients on a sufficient diet (group 2), Jymphocytes from nutritionally sufficient donors were not effective in deficient recipients (group 3). These results indicated that functional immune lymphocytes were produced by iron and protein deficient rats.

\section{Discussion}

Depression of the immune response has been observed in both iron (Nalder et al., 1972; MacDougall et al., 1975) and protein (Jose et al., 1973; Gebhardt and Newberne, 1974) deficiency and an immune defect has been implicated in the suppressed rejection of $N$. brasiliensis from iron and protein deficient rats (Bolin et al., 1977). The purpose of this present study was to determine whether cell mediated immunity was suppressed in deficient animals using the technique of syngeneic lymphocyte transfer.

The results show that transfer of immune lymphocytes from donors of either dietary group significantly reduced worm counts in rats on a sufficient diet. Thus lymphocytes from deficient donors were able to function effectively in iron and protein sufficient rats, as determined by their capacity to expel parasites. In contrast, cells from either iron and protein sufficient or deficient animals did not reduce worm counts in deficient recipient rats. These results indicate that delayed worm expulsion in iron and protein deficiency is not due to a permanent defect in the immunologically specific component of the response involving lymphocyte function.

Thus delayed parasite expulsion in iron and protein deficiency could be due to some factor which reversibly blocks lymphocyte function, or to one or more defects in the rejection mechanism not involving sensitised lymphocytes. Reversible blockade of lymphocyte function has been reported previously in lactating rats, where inhibition of induced lymphoid cells into effector cells has been observed (Kelly and Dineen, 1973). Multiple defects in the immune response have also been reported in iron and protein deficient rats, involving impaired humoral immunity (Nalder et al., 1972; Good et al., 1976), cell mediated immunity (Jose et al., 1973; Gebhardt and Newberne, 1974), and bone marrow function (Aschkenasy, 1957; Sood et al., 1965). In addition the myeloid-amine response is altered with reduction in eosinophil

Table 2 Effect of lymphocyte transfer on expulsion of Nippostrongylus brasiliensis from iron and protein sufficient and deficient rats

\begin{tabular}{|c|c|c|c|c|}
\hline Dietary status of donor rats & Group no. & Dietary status of recipient rats & $\begin{array}{l}\text { Total worm counts on day } 10 \\
\text { after infection. (mean } \pm S E)\end{array}$ & P value \\
\hline $\begin{array}{l}\text { Sufficient } \\
\text { Deficient } \\
\text { Sufficient } \\
\text { Deficient }\end{array}$ & $\begin{array}{l}1 \\
2 \\
3 \\
4 \\
5\end{array}$ & $\begin{array}{l}\text { Sufficient } \\
\text { Sufficient } \\
\text { Deficient } \\
\text { Deficient } \\
\text { Dietary status of infection controls } \\
\text { Sufficient } \\
\text { Deficient }\end{array}$ & $\begin{aligned} 5 & \pm 1 \cdot 1 \\
17 & \pm 7 \cdot 9 \\
269 & \pm 43 \cdot 7 \\
298 & \pm 52 \cdot 6 \\
275 & \pm 44 \cdot 4 \\
320 & \pm 50 \cdot 0\end{aligned}$ & $\begin{array}{l}\text { GP } 1 \text { v } 5 \& 6 \\
<0.01 \\
\text { GP } 2 \text { v } 5 \& 6 \\
<0.01\end{array}$ \\
\hline
\end{tabular}

Data transformed $\log _{10}(x+1)$ for analysis of variance after which Student's $t$ test was employed for individual comparisons. 
counts and increased small bowel mucosal histamine in protein deficiency (Wells, 1962).

The complex interaction between nutrition, infection, and immunity clearly has important clinical implications for malnourished communities. The nutritional status of an individual alters his resistance to infection and may well influence the effectiveness of vaccination procedures and drug treatment regimes. Administration of transfer factor in malnourished man has met with little success in combating infection (Walker et al., 1975; Jose et al., 1976), and it is relevant to know more about the site of the immune defect in malnutrition. Studies are currently under way to assess the effect of bone marrow and serum transfer on the expulsion of $N$. brasiliensis in iron and protein deficient rats.

We would like to thank Miss Glenda Walsh, Miss Margaret Fagan, $\mathrm{Mr}$ Christopher Porter, and Mr D. Griffin for their excellent technical assistance. This study was supported by a grant from the National Health and Medical Research Council of Australia.

\section{References}

Aschkenasy, A. (1957). On the pathogenesis of anemias and leukopenias induced by dietary protein deficiency. American Journal of Clinical Nutrition, 5, 14-25.

Bolin, T. D., Davis, A. E., Cummins, A. G., Duncombe, V. M., and Kelly, J. D. (1977). Effect of iron and protein deficiency on the expulsion of Nippostrongylus brasiliensis from the small intestine of the rat. Gut, 18, 182-186.

Bolin, T. D., McKern, A., and Davis, A. E. (1971). The effect of diet on lactase activity in the rat. Gastroenterology, $60,432-437$.

Dineen, J. K., and Kelly, J. D. (1973). Expulsion of Nippostrongylus brasiliensis from the intestine of rats: the role of a cellular component derived from bone marrow. International Archives of Allergy and Applied Immunology, 45, 759-766.

Dineen, J. K., Kelly, J. D., and Love, R. J. (1973). The competence of lymphocytes obtained from immune and non-immune donors to cause expulsion of Nippostrongylus brasiliensis in the rat (DA strain). International Archives of Allergy and Applied Immunology, 45, 504-512.

Duncombe, V. M., Bolin, T. D., Davis, A. E., and Kelly, J. D. (1978). The effect of iron and protein deficiency on the development of acquired resistance to reinfection with Nippostrongylus brasiliensis in rats. American Journal of Clinical Nutrition. (In press.)

Gebhardt, B. M., and Newberne, P. M. (1974). Nutrition and immunological responsiveness. T-cell function in the offspring of lipotrope and protein deficient rats. Immunology, 26, 489-495.

Good, R. A., Fernandes, G., Yunis, E. J., Cooper, W. C., Jose, D. G., Kramer, T. R., and Hanson, M. A. (1976). Nutritional deficiency, immunologic function, and disease. American Journal of Pathology, 84, 599-614.

Jones, V. E., and Ogilvie, B. M. (1971). Protective immunity to Nippostrongylus brasiliensis: the sequence of events which expels worms from the rat intestine. Immunology, 20, 549-561.

Jose, D. G., Stutman, O., and Good, R. A. (1973). Long term effects on immune function of early nutritional deprivation. Nature, 241, 57-58.

Jose, D. G., Ford, G. W., and Welch, J. S. (1976). Therapy with parent's lymphocyte transfer factor in children with infection and malnutrition. Lancet, 1, 263-266.

Kelly, J. D., and Dineen, J. K. (1972). The cellular transfer of immunity to Nippostrongylus brasiliensis in inbred rats (Lewis strain). Immunology, 22, 199-210.

Kelly, J. D., and Dineen, J. K. (1973). The suppression of rejection of Nippostrongylus brasiliensis in Lewis strain rats treated with ovine prolactin. The site of the immunological defect. Immunology, 24, 551-558.

Kelly, J. D., Dineen, J. K., Goodrich, B. S., and Smith, I. D. (1974). Expulsion of Nippostrongylus brasiliensis from the intestine of rats. Role of prostaglandins and pharmacologically active amines (histamine; 5-hydroxytryptamine) in worm expulsion. International Archives of Allergy and Applied Immunology, 47 458-465.

Leigh, L. C. (1956). Methods of culture and collection of Nippostrongylus muris. Journal of the Institute for Science and Technology, 2, 21.

Macdougall, L. G., Anderson, R., McNab, G. M., and Katz, J. (1975). The immune response in iron-deficient children: impaired cellular defence mechanisms with altered humoral components. Journal of Pediatrics, 86, 833-843.

Nalder, B. N., Mahoney, A. W., Ramakrishnan, R., and Hendricks, D. G. (1972). Sensitivity of the immunological response to the nutritional status of rats. Journal of Nutrition, 102, 535-541.

Stanfield, J. P. (1966). The diarrhoea-malnutrition cycle. Journal of Tropical Paediatrics, 12, 53.

Sood, S. K., Deo, M. G., and Ramalingsawami, V. (1965). Anemia in experimental protein deficiency in the rhesus monkey with special reference to iron metabolism. Blood, 26, 421-432.

Walker, A. H., Garcia, R., Pate, P., Mata, L. J., and David, J. R. (1975). Transfer factor in the immune deficiency of protein-calorie malnutrition: a controlled study with 32 cases. Cellular Immunology, 15, 372-381.

Wells, P. D. (1962). Mast cell, eosinophil and histamine levels in Nippostrongylus brasiliensis infected rats. Experimental Parasitology, 12, 82-101. 